\title{
TREATMENT OF ACUTE RHEUMATISM WITH BUTAZOLIDIN
}

\author{
BY
}

\author{
J. FLEMING and G. WILL \\ From the Royal Infirmary, Greenock
}

(RECEIVED FOR PUBLICATION MARCH 26, 1953)

A favourable experience of Butazolidin in the treatment of rheumatoid arthritis and the experimental reports that it appears to influence the resolution of inflammatory exudates, suggested that it might be of use in treating acute rheumatism.

\section{Case Reports}

(1) Female, aged 17, had been treated for rheumatic fever 3 years ago, but it appeared to have been a mild attack, and she had been well since; 6 days before admission she had developed pain, stiffness, and swelling of both ankles, and the knees, hands, and shoulders also became involved; 3 days later she had sternal and interscapular pain with cough, and complained also of anorexia, headache, profuse perspiration, and occasional vomiting. The joint pains responded to some extent to salicylate.

Examination.-On admission (temperature $101 \cdot 2^{\circ} \mathrm{F}$, pulse 110 , respirations 25 ), she complained of severe sternal pain and was dyspnoeic and cyanosed. There was no notable swelling of the joints, but the knees were tender. The heart sounds were regular, very soft, and a systolic murmur was present at the apex. A soft to-andfro friction rub was heard at the base. The erythrocyte sedimentation rate was $94 \mathrm{~mm}$./hr (Westergren). On the 9th day of illness an area of bronchial breathing was noted at the left base and pericardial friction persisted. Her condition deteriorated, and three days later the fever increased with rapid pulse (130) and respirations (40).

Progress.-Two days later she developed a circinate erythema over the abdomen, buttocks, and backs of the thighs, and there was a recurrence of severe joint pains with increase in praecordial pain. She was now very dyspnoeic and cyanosed, and coarse pericardial friction was heard and felt over the whole praecordium. Streptomycin $\frac{1}{2} \mathrm{~g}$. twice daily was added on the 15 th day of illness, but there was no response and she deteriorated rapidly to a moribund condition on the 22 nd day of illness.

Therapy.-All other treatment was discontinued and she was given three tablets Butazolidin daily (Fig. 1). The next morning there was a remarkable improvement; she was comfortable, and asked for food, and the tempera-

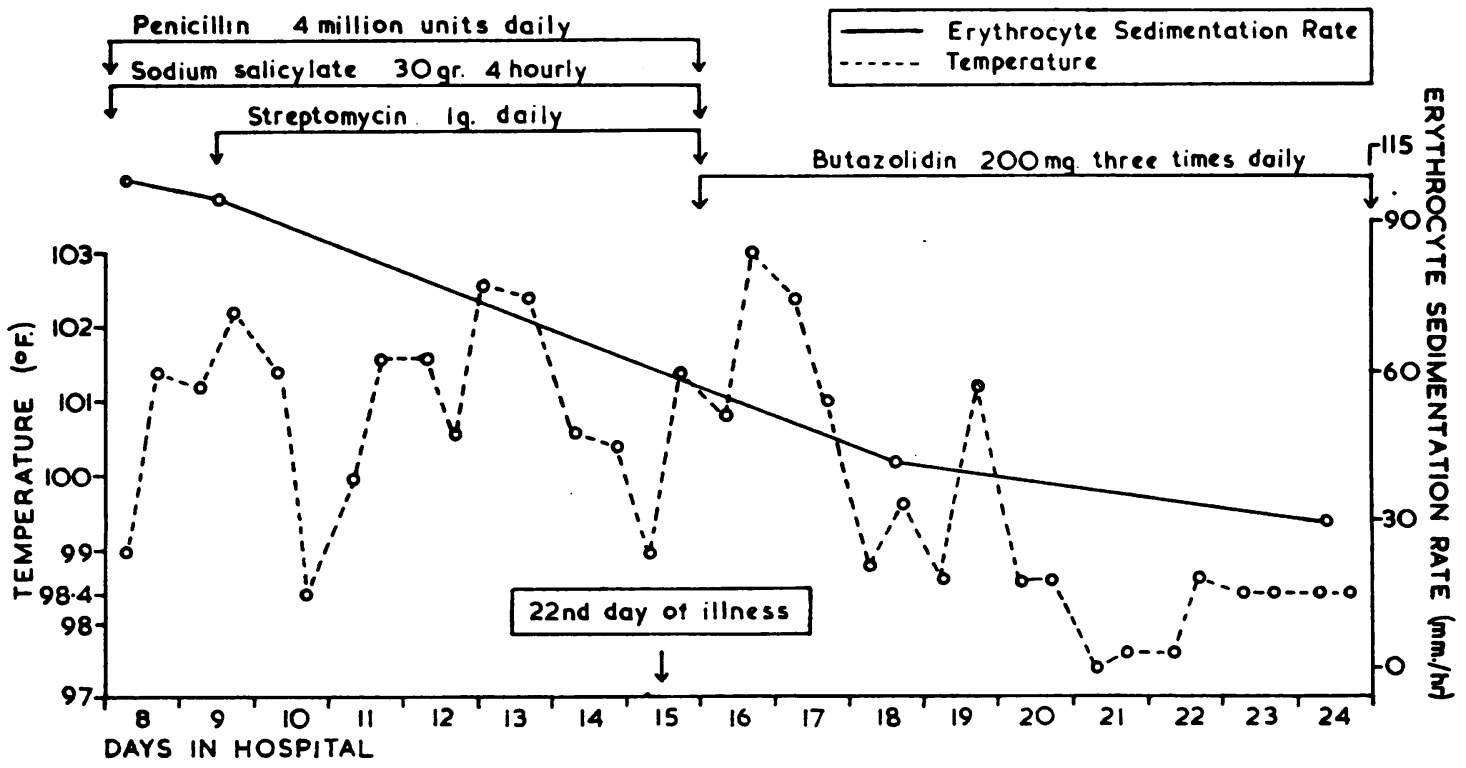

Fig. 1.-Case 1. 
ture fell to normal levels in 24 hours. Two days later the pericardial friction had completely gone and has not recurred, and a week later the erythrocyte sedimentation rate was $38 \mathrm{~mm}$./hr. There was a gradual improvement in the quality of the heart sounds, and the first sound, which had been obscured by a soft murmur, was clearly audible and pure by the 40 th day.

A favourable convalescence with a continued fall in the erythrocyte sedimentation rate suggests that she is likely to make a complete recovery.

(2) Schoolboy, aged 11, had developed a cold, with cough and spit, but no sore throat, 12 days before admission. A week later he fell and thought he had hurt his right ankle. An $x$ ray was negative, but 2 days later he still had pain in the left ankle and also in the wrist. He was now fevered and complained of severe headache.

Examination.-On admission (temperature $104^{\circ} \mathrm{F}$., pulse 120 , respirations 30 ), he was complaining bitterly of pain in the right and left legs. The right ankle and most of the leg was very swollen, red, and tender, and the left ankle and wrists were affected to a lesser extent.

Therapy.-The pain responded to salicylate, but fever continued, the right leg remained acutely inflamed, and the erythrocyte sedimentation rate continued to rise to $128 \mathrm{~mm}$./hr. The salicylate was now discontinued and he was given Butazolidin, $200 \mathrm{mg}$. three times daily. During the next $24 \mathrm{hrs}$ the temperature settled, and remained normal. The joints improved rapidly and were normal in appearance 4 days later, and the patient was now completely comfortable. Three days later the erythrocyte sedimentation rate was $95 \mathrm{~mm}$./ hr, and a soft murmur, which had been noted at the apex during the earlier stages, could not be detected. He has continued to make a favourable convalescence.
(3) Schoolboy, aged 9, had a severe sore throat 5 weeks before admission; it improved in the next few days, and he seemed well until 10 days later when he had pain in the $?$ knees and ankles. There was some response to aspirin, but he continued to have low fever and a high erythrocyte $\stackrel{\oplus}{\rightarrow}$ sedimentation rate. In the fifth week an apical systolic murmur was heard.

Examination.-On admission there was only a little $\frac{\overline{\bar{S}}}{\vec{\sigma}}$

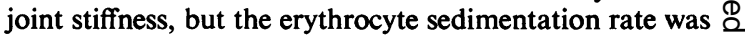
$95 \mathrm{~mm} . / \mathrm{hr}$, and low fever continued. The first apical @) sound was partially replaced by a soft murmur, and the pulmonic sound was loudly accentuated.

Therapy.-There was no improvement during treatment $\vec{\omega}$ with aspirin and penicillin, and 4 weeks after admission Butazolidin, $200 \mathrm{mg}$. three times daily, was substituted. During the next few days the temperature fell to normal ? levels and the erythrocyte sedimentation rate slowly $\vec{N}$ improved. The cardiac murmur was unchanged.

(4) Schoolgirl, aged 15, had had two previous attacks 0 of acute rheumatic fever, which had responded to salicylate therapy, but resulted in a mitral stenosis, which, $\bar{c}$ until the present illness, had caused no symptoms; $\overline{5}$ 3 weeks before admission she developed for the third time acute rheumatic fever with severe joint swelling, $\overrightarrow{0}$ pain, and tenderness in both knees, ankles, elbows, and $\mathcal{\omega}$ shoulder. During the next 10 days the pain and tenderness responded to $15 \mathrm{gr}$. aspirin four times daily, but the temperature remained around $101 \cdot 5^{\circ} \mathrm{F}$.

Examination.-On admission (temperature $101 \cdot 6^{\circ}$ F.) she looked ill, and there was swelling and acute tenderness of the knees, ankles, and right elbow.

Therapy.-She was treated with Butazolidin, $200 \mathrm{mg}$. thrice daily, and there was a notable response of the temperature and joint swelling (Fig. 2). After 5 days the

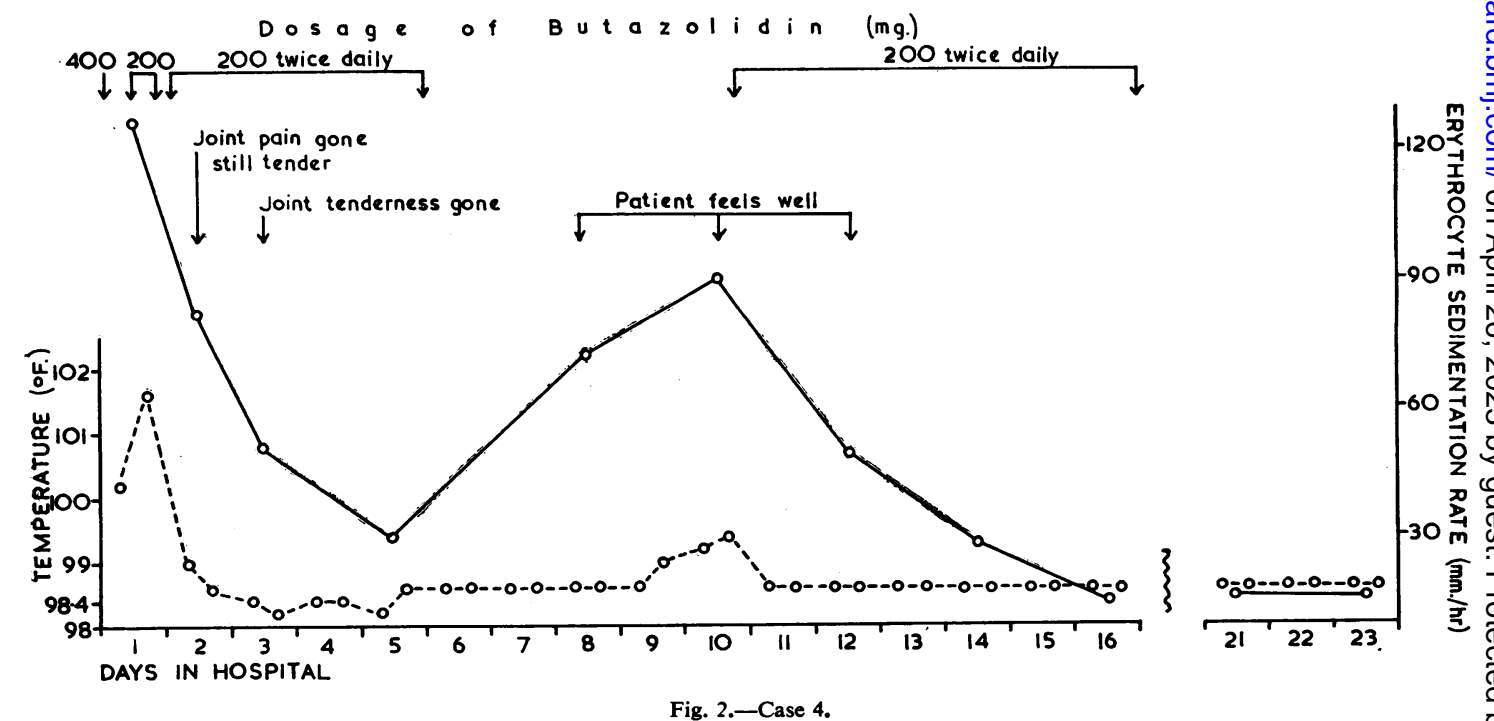

Fig. 2.-Case 4. 
drug was withdrawn and the patient continued to feel well till the 9th day, when there was a rise of temperature and erythrocyte sedimentation rate. Butazolidin in the same dose produced an immediate similar response; on the 16th day the drug was discontinued, and there has been no relapse. There is no evidence of further cardiovascular damage.

(5) Schoolboy, aged 12, with no previous history of rheumatic disease, 14 days before admission complained of sore throat, which cleared up after 3 days' treatment with sulphonamide. A week before admission he developed acute pain and stiffness in the right knee, which became red and swollen, and was followed by the left elbow and right wrist. There was high fever $\left(102 \cdot 5^{\circ}\right.$ to $103 \cdot 5^{\circ} \mathrm{F}$.), and no response to $15 \mathrm{gr}$. aspirin four times daily.

Examination.-On admission (temperature $103 \cdot 2^{\circ} \mathrm{F}$.), he was very ill, with severe inflammation and tenderness of the left elbow, wrist, and right knee.

Therapy.-Both fever and joint pains responded to Butazolidin, $200 \mathrm{mg}$. twice daily. Butazolidin was stopped on the 13th day and he has continued to make a favourable convalescence. There is no evidence of cardiac involvement.

These unexpectedly favourable results raise the hope that further experience will establish Butazolidin as a useful drug in the treatment of acute rheumatic diseases. The present treatment with sodium salicylate is unsatisfactory, both because of the unpredictable results, and because of the huge doses required. In these cases, a small dose of Butazolidin, consisting of one or two tablets daily, was sufficient to produce a response. In our experience with similar doses in many cases of chronic rheumatism, toxic reactions are infrequent and of small significance.

\section{Summary}

The use of Butazolidin is reported in five cases of acute rheumatism, which showed little or no response to salicylates.

In each case there was a rapid improvement in joint pain, temperature, and erythrocyte sedimentation rate, and the patient made a good recovery.

There were no toxic reactions. Relapse on withdrawal of Butazolidin, which occurred in one case, was quickly checked by a few additional doses.

We are indebted to Dr. J. P. Currie, Glasgow Royal Infirmary, for details of Cases 4 and 5.

\section{Traitement du rhumatisme articulaire aigu par la butazolidine \\ Résumé}

On relate l'emploi de la butazolidine dans cinq cas de rhumatisme articulaire aigu totalement ou partiellement réfractaire aux salicylates.

Dans tous les cas on nota une amélioration rapide de la douleur articulaire, de la température et de la sédimentation globulaire et le rétablissement des malades.

Il n'y eut pas de réactions toxiques. Une rechute qui survint dans un cas après la suppression de la butazolidine, fut rapidement enrayée par quelques doses additionnelles.

\section{Tratamiento del reumatismo poliarticular agudo con butazolidina \\ SUMario}

Se relata el empleo de la butazolidina en cinco casos de reumatismo poliarticular agudo, totalmente o parcialmente refractario a los salicilatos.

En todos los casos se notó una mejoría rápida del dolor articular, de la temperatura y de la sedimentación eritrocitaria y los enfermos recobraron la salud.

No hubo reacciones tóxicas. Al discontinuar la butazolidina hubo una recaída, rapidamente reprimida con pocas dosis adicionales. 